\title{
Student Counselors ' Moral, Intellectual, and Professional Ethical Identity Development
}

Jessica Lloyd-Hazlett

jessica.lloyd-hazlett@utsa.edu

Victoria A. Foster

College of William and Mary, vafost@wm.edu

Follow this and additional works at: https://scholarworks.wm.edu/aspubs

\section{Recommended Citation}

Lloyd-Hazlett, Jessica and Foster, Victoria A., Student Counselors ' Moral, Intellectual, and Professional Ethical Identity Development (2017). COUNSELING AND VALUES, 62(1).

10.1002/cvj.12051

This Article is brought to you for free and open access by the Arts and Sciences at W\&M ScholarWorks. It has been accepted for inclusion in Arts \& Sciences Articles by an authorized administrator of W\&M ScholarWorks. For more information, please contact scholarworks@wm.edu. 


\title{
Student Counselors' Moral, Intellectual, and Professional Ethical Identity Development
}

\begin{abstract}
Jessica Lloyd-Hazlett and Victoria A. Foster
Professional identity is characterized by the integration of individuals' professional and personal selves. The authors used a multiple regression design to examine counselor professional ethical identity development, with specific attention to moral and intellectual development. Student counselors $(N=59)$ completed the Modified SubjectObject Interview (Monson \& Hamilton, 2010), Defining Issues Test-2 (Rest, Narvaez, Bebeau, \& Thoma, 1999a), and Learning Environment Preferences scale (Moore, 1987). Moral development was the most significant predictor of professional ethical identity development. Preparatory and research strategies to enhance professional ethical identity formation are discussed.
\end{abstract}

Keywords: professional identity, cognitive development, counselor education

rofessional identity represents an integration of personal attributes and training in the context of a professional community (Nugent \& Jones, 2009). The identity of professions, such as counseling, that serve the public varies from other fields based on inherent commitments to prioritize the interests of clients over personal gain (Bebeau \& Monson, 2012). The ACA Code of Ethics (American Counseling Association [ACA], 2014) charges professional counselors to be respectful of differences; avoid imposing personal values on clients; and, above all, do no harm (Standard A.4.).

The professional responsibility to prioritize client interests has served as an epicenter for contemporary, groundbreaking litigation in counselor education, such as Keeton v. Anderson-Wiley (2010) and Ward v. Wilbanks (2009). In each of the cited lawsuits, faculty within an accredited counselor training program dismissed a student for refusing to work with sexual minority clients.

Jessica Lloyd-Hazlett, Department of Counseling, University of Texas at San Antonio; Victoria A. Foster, School Psychology and Counselor Education, College of William \& Mary. Correspondence concerning this article should be addressed to Jessica Lloyd-Hazlett, Department of Counseling, College of Education and Human Development, University of Texas at San Antonio, 501 West César E. Chávez Boulevard, San Antonio, TX 78207 (e-mail: jessica.lloyd-hazlett@utsa.edu).

(C) 2017 by the American Counseling Association. All rights reserved. 
The programs offered remediation opportunities, but the students declined, citing discrimination from the university. Tennessee recently passed legislation permitting counselors to refuse to treat clients based on the counselor's "sincerely held religious beliefs" (Tenn. SB 1556/HB 1840, 2016), highlighting the contentious climates that continue to surround counselors' professional ethical identity and responsibilities.

Revisions to the ACA Code of Ethics (ACA, 2014) reflect a significant effort to clarify ethical client referral processes and to differentiate competencebased versus values-based referrals. However, principles and codes alone are an insufficient means to ensure ethical behavior among professionals (Linstrum, 2009; Rest, Narvaez, Bebeau, \& Thoma, 1999b). Counselors disagree on the ethicality of a wide range of behaviors and dilemmas, with divergences most profound around value-laden issues (Neukrug \& Milliken, 2011). Furthermore, counselors at different levels of development understand and apply codes of ethics inconsistently (Lambie, Hagedorn, \& Ieva, 2010; Linstrum, 2009). Thus, beyond the simple transmission of knowledge of ethical codes, counselor educators hold a chief responsibility to promote the development of an internalized professional counselor identity that will enable students to uphold professional ethical commitments to society.

An integration of professional and personal worldviews is a mark of counselor professional identity development (Gibson, Dollarhide, \& Moss, 2010). Using a grounded theory design, Auxier, Hughes, and Kline (2003) highlighted the emergence of a therapeutic self during counselor identity development, which combines the professional (roles, decisions, ethics) and personal (values, morals, perception). This therapeutic self provides a frame of reference for ethical practice, decision making, and problem solving (Auxier et al., 2003). Although researchers have given significant attention to defining the professional identity of counselors (Woo, Henfield, \& Choi, 2014), less research has focused on professional and ethical formation (Owens \& Neal-McFall, 2014; Riechel, 2013).

As described in the preamble to the ACA Code of Ethics (ACA, 2014), "professional values are an important way of living out an ethical commitment" (p.3). Ethical behavior extends beyond knowledge to also include ethical sensitivity, motivation, and action (Rest et al., 1999b). Counselors must be sensitive to the salient ethical aspects of situations and the potential impacts of decisions on concerned parties. They must also be motivated to prioritize ethical responsibilities and be willing to take necessary action. In short, ethical behavior entails more than compliance with externally imposed responsibilities. Instead, one must integrate ethical behavior into his or her identity. The purpose of the current study was to explore student counselors' professional ethical identity development (Bebeau \& Lewis, 2003; Monson \& Hamilton, 2010), which refers to the level of integration across student counselors' personal and professional ethical commitments. We also examined the relationships between professional 
ethical identity development, moral development (Kohlberg, 1984; Rest et al., 1999b), and intellectual development (Perry, 1970).

\section{Professional Ethical Identity Development}

Cognitive developmental theories (i.e., constructivist self-development, moral development, intellectual development, and ego development) describe frameworks individuals hold for understanding the self, others, and complex social experiences. Researchers have found positive relationships between advanced cognitive developmental statuses and a number of desirable counseling behaviors. These include greater tolerance of ambiguity (McAuliffe \& Lovell, 2006), multiple perspective taking (Basseches, 2003), ethical reasoning (Lambie et al., 2010; Lambie, Ieva, \& Mullen, 2011), and multicultural competence (Cannon, 2008; Endicott, Bock, \& Narvaez, 2003).

Kegan's $(1982,1994)$ foundational theory of constructivist selfdevelopment (subject-object relationships) offers a valuable lens for considering student counselors' professional ethical identity development. According to Kegan, object relationships exist when one perceives aspects of self or experience with sufficient cognitive distance to be able to look and reflect upon them. Such objective self-awareness allows one to be in control of, rather than controlled by, the aspect of self. In contrast, being subject to aspects of self entails embeddedness or a lack of awareness of one's own perceptions and experiences. For example, one might feel anger but not be overcome by, or held subject to, this emotion. This demonstrates emotional regulation as an aspect of self that is object to the individual. One may reframe counselor reflexivity, or a lack thereof, in terms of subject-object delineations. Nonreflexive thinkers may be seen as subject to their personal values and, thus, unable to see outside of them. Reflexive thinkers are better able to take their personal beliefs and values as object and to view multiple perspectives, a developmental achievement integral to the professional responsibility of counselors to prioritize the interest of clients (ACA, 2014).

Bebeau and Lewis (2003) delineated a process of professional ethical identity development grounded in Kegan's $(1982,1994)$ theory. The model outlines transitions in the degree of internalization and congruence between the values and commitments of one's profession and one's personal values. At higher stages of development, counselors view a violation of the ethical commitments of the profession as a violation of the self (Bebeau \& Monson, 2012; Monson \& Hamilton, 2010).

The first identifiable stage of professional ethical identity development is the independent operator (Stage 2). The individual views the self and the world in terms of personal interests and concrete role expectations. In this stage, one understands professionalism as meeting fixed role obligations 
and being "correct." Within the next developmental position, team-oriented idealist (Stage 3), individuals have an increased capacity to balance multiple perspectives. However, individuals may have difficulty seeing boundaries between self and others. A more integrated identity composed of both personal values and those of the profession emerges for the self-defining professional (Stage 4). Individuals at this stage use reflective practice to resolve competing ideas and roles. Furthermore, individuals are able to critically assess their profession while remaining strongly committed to it (Bebeau \& Lewis, 2003; Monson \& Hamilton, 2010).

Researchers have applied professional ethical developmental theory to studies across a range of fields, including dentistry (Monson \& Bebeau, 2009), clergy (C. R. Foster, 2008), military cadets (Bartone, Snook, Forsythe, Lewis, \& Bullis, 2007), medical professionals (Leach, 2008), and lawyers (Monson \& Hamilton, 2010). In the only known study to date specifically assessing counselor professional ethical identity development, Riechel (2013) examined the relationships among school counselors' professional ethical identity development, moral reasoning, and attitudes toward confidentiality with minors. There was a moderate correlation between school counselor professional ethical identity development and moral development. When making the decision to break confidentiality with minors, school counselors at higher levels of professional ethical identity development were more likely to consider students' ages and less likely to consider compliance with school district policies than those at lower developmental positions. Riechel's findings support that professional identity mediates school counselors' ethical approaches. However, a better understanding of counselors' professional ethical identity development is needed. To address this gap, we used a multiple regression design to explore the following research questions:

Research Question 1: What are student counselors' developmental positions across domains of professional ethical identity development, moral development, and intellectual development? (univariate)

Research Question 2: What relationships exist among student counselors' professional ethical identity development, moral development, and intellectual development? (bivariate)

Research Question 3: What is the individual and combined power of moral development and intellectual development in predicting student counselors' professional ethical identity development? (multivariate)

\section{Method}

\section{Sampling}

After receiving approval from the institutional review board, we invited (via e-mail) all CACREP liaisons at accredited master's-level community / 
clinical mental health counseling programs in the United States $(N=229$; www.cacrep.org/directory/) to participate. Sixty program liaisons (26\%) agreed to distribute the electronic survey link to counseling students in their programs who met inclusion criteria. The 60 program liaisons distributing the survey link represented the following Association for Counselor Education and Supervision regions: North Atlantic, nine (15\%); North Central, 19 (32\%); Rocky Mountain, two (3\%); Southern, 25 (42\%); and Western, five ( $8 \%)$. Compared with the regional distribution of CACREPaccredited community/clinical mental health counseling programs, the sample reflects some underrepresentation of the North Atlantic and Rocky Mountain regions. Fifteen private (25\%) and 12 religiously affiliated $(20 \%)$ programs were represented. A total of 275 counseling students accessed the research survey via Qualtrics, of which 66 (24\%) completed the survey. We were not able to score data from seven participants, yielding a final sample size of 59 .

\section{Participants}

The participants' $(N=59)$ ages ranged from 22 to 68 years, with a median age of 28 years $(M=32.2, S D=10.4)$. Forty-seven participants $(79.7 \%)$ identified as female, 11 as male $(18.6 \%)$, and one as transgender $(1.7 \%)$. With regard to race/ethnicity, $86.4 \%$ of the participants self-identified as Caucasian, $5.1 \%$ as biracial, $3.4 \%$ as Hispanic, $1.7 \%$ as African American, $1.7 \%$ as Asian/Pacific Islander, and $1.7 \%$ as other (writing in "American"). Eleven participants reported not yet taking an ethics courses, 38 reported having taken one ethics course, and 10 reported previously taking two or more ethics courses.

\section{Instruments and Scoring}

We compiled the informed consent, brief demographic questionnaire, and developmental assessments and made them available through Qualtrics. It took an estimated 45-60 minutes to complete the survey instruments. To encourage participation, participants were entered to win one of ten $\$ 25$ gift cards.

Modified Subject-Object Interview. We used the Modified Subject-Object Interview (MSOI) to measure participants' professional ethical identity development. We modified the original MSOI items (Monson \& Hamilton, 2010) for appropriateness to the counseling profession, and the modified items included the following: (a) "Personally, how do you understand the meaning of professionalism? How did you come to this understanding?" (b) "What will you expect of yourself as you work toward becoming a counselor? What will the profession expect of you?" (c) "What conflicts do you expect to experience (i.e., between your responsibility to yourself and to others-clients, family, community, profession)?" (d) "What would 
be the worst thing for you if you failed to live up to the expectations you have set for yourself?" and (e) "What would be the worst thing for you if you failed to live up to the expectations of your clients, the profession, and society?"

We asked participants to provide a response of at least one full paragraph for each MSOI question. Following data collection, we coded stage content of the MSOI responses and designated one of six overall stage ratings: Stage 2, independent operator; Stage 2/3, transition between Stages 2 and 3; Stage 3, team-oriented idealist; Stage 3/4, transition between Stages 3 and 4; and Stage 4, self-defining professional. The first author, an educational psychologist who contributed to the development of the MSOI, completed the MSOI scoring (Bebeau \& Lewis, 2003). The two coders independently analyzed a set of 10 randomly selected essays. The coders discussed and resolved any preliminary differences in stage ratings within the set. The two coders then each reviewed and scored the entire data set of 59 essays. Intercoder agreement across the entire sample was $93 \%$. Residual differences across coders were reconciled to yield a final overall stage rating for each participant.

Because of the more emergent status of the MSOI, limited information is available on instrument reliability and validity. However, such data is available for the traditional Subject-Object Interview (SOI; Lahey, Souvaine, Kegan, Goodman, \& Felix, 1988) and suggests, by extension, moderate reliability and validity of the MSOI. Cronbach's alphas (within one discrimination) for the SOI range from .82 to 1.00 , with a median of .96. This is comparable to Loevinger's Sentence Completion Test, a well-established and theoretically comparable instrument to the MSOI. Test-retest reliability for the original SOI is .83 (Lahey et al., 1988).

Defining Issues Test-2. We used the Defining Issues Test-2 (DIT-2; Rest, Narvaez, Bebeau, \& Thoma, 1999a) to assess moral development. Moral development relates to individuals' understandings of morality, as defined by principles about how individuals should treat each other. The DIT-2 includes five moral dilemmas. After reading the dilemmas, participants were asked to rate the importance of 12 items according to their value in making a decision using a 5-point Likert-type scale ranging from 1 (no importance) to 5 (great importance). Participants then ranked the four items they considered most important in making their decision. Ratings and rankings reflected the moral developmental level participants most readily used when making decisions about the moral dilemmas. We sent the raw data from the DIT-2 to the Center for the Study of Ethical Development for external scoring.

Scores on the DIT-2 represent three broad levels of moral reasoning: preconventional, conventional, and postconventional. Preconventional moral development is characterized by egocentric concern for self and avoidance of external punishment. Conventional levels reflect externally ascribed definitions of morality, with concern for upholding social 
norms. Postconventional schemas are marked by an ability to recognize the potential limitations of social conventions, with morality individually defined based on consideration of the greater good of society. The P score, derived from participants' rankings of postconventional items, serves as the primary DIT-2 index (Bebeau \& Thoma, 2003). The P score represents the proportion of items selected by a participant that reflect postconventional moral developmental considerations. P scores can range from 0 to 95 and translate as the percentage of time an individual prefers postconventional moral reasoning.

Test-retest reliabilities over periods spanning a few weeks to a few months range from .70 to .80 (Bebeau \& Thoma, 2003). Internal consistency is in the high .70s (Rest, 1988). Convergent and divergent correlations to other measures of cognitive development and intelligence range from .20 to .50. Low correlations exist with personal attributes such as gender, socioeconomic status, and personality. Concurrent validity with other measures of moral reasoning ranges from 60 to .70 (Rest, 1988).

Learning Environment Preferences scale. We used the Learning Environment Preferences scale (LEP; Moore, 1987) to assess intellectual development based on Perry's (1970) scheme. Intellectual development relates to how individuals understand the process and nature of knowing, as well as the ethical commitments of knowers. The instrument is composed of 65 questions divided into five domains: (a) view of knowledge and course content, (b) role of the instructor, (c) role of the student and peers in the classroom, (d) classroom atmosphere, and (e) role of evaluation. Participants were asked to rate the significance of each item according to a 4-point Likert-type scale ranging from 1 (not at all significant) to 4 (very significant) and then to select three top statements within each domain. The researchers sent the raw data from the LEP to the Center for the Study of Intellectual Development for external scoring.

The LEP identifies six positions of intellectual development, which fall into four major categories. The first category, dualism (Positions 1 and 2), is characterized by dichotomous cognitive structures, with truth externally ascribed and unquestioned. The second category, multiplicity (Positions 3 and 4 ), entails the recognition of multiple perspectives. Transition to the third category, contextual relativism (Position 5), is marked by a growing capacity for metacognition and awareness of oneself as an active maker of meaning. Finally, commitment within relativism (Position 6) involves conscious adoption of schemas for knowing within a context of legitimate alternatives. The LEP produces two scores: an overall cognitive complexity index (CCI) and a position rating responding to the Perry's (1970) framework. CCI scores reflect a single numerical index along a continuous scale of intellectual development from 200 to 500 . CCI scores approximate position ratings, so a CCI score of 200 is roughly equivalent to Position 2.

Moore $(1987,1989)$ reported positive correlations between position ratings, CCI scores, and undergraduate classification in both longitudinal and 
cross-sections studies. Internal consistency of the LEP is in the high .60s for each of the five domains and in the $.80 \mathrm{~s}$ for the six epistemological positions. Test-retest reliability for CCI scores is .89 (Moore, 1987).

\section{Results}

This study used three tiered levels of statistical analyses. First, we computed descriptive statistics for the MSOI, DIT-2, and LEP. The mean, standard deviation, and frequency for each instrument are reported in Table 1 . We found the DIT-2 (60 items; $\alpha=.71$ ) and LEP (65 items; $\alpha=.69$ ) to be reliable. The second level of analysis examined bivariate relationships among the three developmental measures. As hypothesized, significant positive correlations existed (see Table 1). The strongest correlation emerged between moral development and intellectual development, $r$ (57) $=.42, p<.01$, one-tailed, followed by moral development and professional ethical identity development, $r(57)=.37, p=.002$, one-tailed, and intellectual development and professional ethical identity development, $r(57)=.30, p=.010$, one-tailed.

The final level of analysis examined the predictive utility of moral development and intellectual development for professional ethical identity development. We used a stepwise regression because of the exploratory nature of this study. Specifically, no studies to date have explored the theoretical or empirical relationships between professional

\section{TABLE 1}

Descriptive Statistics and Correlations Among Developmental Measures

\begin{tabular}{|c|c|c|c|c|c|c|c|}
\hline Measure & $M$ & $S D$ & $n$ & $\%$ & 1 & 2 & 3 \\
\hline 1. MSOI & 3.16 & 0.49 & & & - & & \\
\hline Stage 2 & & & 2 & 3.4 & & & \\
\hline Stage $2 / 3$ & & & $\overline{9}$ & 15.3 & & & \\
\hline Stage 3 & & & 22 & 37.3 & & & \\
\hline Stage $3 / 4$ & & & 20 & 33.9 & & & \\
\hline Stage 4 & & & 6 & 10.2 & & & \\
\hline 2. DIT-2 & 43.29 & 14.61 & NA & NA & $.37^{* *}$ & - & \\
\hline 3. LEP & 384.83 & 35.60 & & & $.30^{*}$ & $.42^{* *}$ & - \\
\hline Position 2 & & & 0 & 0.0 & & & \\
\hline Position $2 / 3$ & & & 2 & 3.4 & & & \\
\hline Position 3 & & & 1 & 1.7 & & & \\
\hline Position $3 / 4$ & & & 14 & 23.7 & & & \\
\hline Position 4 & & & 30 & 50.8 & & & \\
\hline Position 4/5 & & & 12 & 20.3 & & & \\
\hline Position 5 & & & 0 & 0.0 & & & \\
\hline Position 6 & & & 0 & 0.0 & & & \\
\hline
\end{tabular}

Note. $N=59$. MSOI = Modified Subject-Object Interview; DIT-2 = Defining Issues Test-2; LEP $=$ Learning Environment Preferences scale.

${ }^{*} p<.05 .{ }^{* *} p<.01$. 
ethical identity development, moral development, and intellectual development. When we applied moral development and intellectual development to a regression model, the participants' DIT-2 P scores were the only significant predictors of professional ethical identity development. This meant that intellectual development did not significantly predict variance in participants' professional ethical identity development beyond the variance accounted for by moral development. The resulting model, which included moral development only, was significant at the .01 level, $F(58)=9.22, p=.004$. Examination of the correlation $(r=.37)$ and multiple correlation squared $\left(R^{2}=.14\right)$ revealed the model was of moderate strength, because it accounted for $13.9 \%$ of variance in professional ethical identity development.

To test the predictive ability of intellectual development for professional ethical identity development, we entered LEP scores using regression methodology. The resulting regression model, which included intellectual development only, was significant at the .05 level, $F(58)=5.73, p=.020$. Examination of the correlation $(r=.30)$ and multiple correlation squared $\left(R^{2}=.09\right)$ revealed the model was of low/moderate strength, accounting for $9.2 \%$ of variance in professional ethical identity development. Overall, moral development and intellectual development were significant predictors of professional ethical identity development individually, but not in combination. Collinearity did not appear to affect the model because none of the tolerance figures were below .20. In addition, assumptions related to normality of errors, constancy of error variance, and independent errors in regression analyses were met.

\section{Discussion}

The current study examined student counselors' professional ethical identity development. The first level of analysis considered student counselors' cognitive developmental positions across domains of intellectual, moral, and professional ethical identity development. Participants' professional ethical identity developmental stages were consistent with Riechel's (2013) findings for a sample of 30 professional school counselors, which is the only other known study examining professional ethical identity development within the counseling field. The distribution and range of the participants' moral and intellectual development levels were also consistent with results from extant studies (Cannon, 2008; Granello, 2002; Lambie et al., 2010, 2011; Linstrum, 2009). Specific to moral development, participants applied postconventional moral judgment schemas $43 \%$ of the time when reasoning through ethical dilemmas. This finding is particularly important because postconventional schemas are congruent with the ethical responsibilities and obligations outlined for members of the counseling profession. Relative to intellectual development, the majority of participants $(n=30,50.8 \%$ ) occupied Position 4 (high multiplicity), 
which is characterized by movement away from dually defined right or wrong answers. This marks an important developmental achievement because multiple perspectives may now be considered. However, the demands of clinical practice may extend beyond the recognition of different perspectives to also include counselors' awareness of their own agency as active meaning makers (Basseches, 2003). Consistent with extant research, no participants achieved relativistic statuses (Positions 5 and 6; Granello, 2002; McAuliffe \& Lovell, 2006). Relativistic statuses are characterized by meta-awareness of knowledge as socially constructed, including the active and subjective constructions of meaning by both clients and counselors in session.

Overall, the participants' modal developmental levels support the existence of a developmental plateau around positions that retain social norms (Moore, 1987). The broad range of scores is also indicative that although possible, cognitive developmental gains are not automatic nor are developmental positions synchronous with chronological age or educational level (Bebeau, 2008; Bebeau \& Monson, 2012). Thus, the role of counselor education becomes clear as a catalyst to transcend developmental hurdles and facilitate the creation of cognitive schemas more adaptive to the professional work of counselors.

\section{Limitations}

Limitations to the sample size and response rate warrant consideration. Of the 229 CACREP-accredited community/clinical mental health counseling programs that we contacted, only 60 program liaisons agreed to distribute the research survey. We did not collect information about the number of student counselors eligible for survey distribution at the contacted counseling programs. Therefore, the total response rate could not be calculated. The sample also included only counseling students in CACREP-accredited programs. Although we designed the inclusion criterion to support greater curricular homogeneity within the sample, the generalizability of the results is more limited. The time it took to complete the study instruments (45-60 minutes) contributed to substantial participant attrition, with only 66 of the 275 (24\%) participants accessing the survey and completing all the instruments. In addition, the majority of participants were White women. It is possible that students who opted to participate in the study were developmentally different from those who did not; similarly, it is possible that those who choose to complete versus discontinue the survey differed. Future researchers choosing to replicate the study should consider the lengthy time requirement and participant attrition in their study designs. Usable data were obtained only from 59 participants, with a sample size of 67 required for a medium effect size at a statistical power level of .80 at the .05 alpha level. Because of the small sample size and increased potential for error, the results of this study are preliminary. 
Limitations of the stepwise regression analyses outlined by Malek, Berger, and Coburn (2007), such as the failure to account for the number of variables considered and inflated $R^{2}$ values, should also be noted when interpreting the results of this study. Future studies may use findings from the present research to inform hierarchical regression analyses, which would suggest that researchers enter moral development prior to intellectual development into models predictive of professional ethical identity development. Potential limitations related to the scope of the instruments also existed. The DIT-2 most readily assesses moral reasoning. Because other components of moral behavior (moral sensitivity, moral courage, moral action) are not as integrated into the instrument, participants' moral developmental levels may have reflected a restricted theoretical range (Rest et al., 1999b). Similarly, because the LEP focuses on knowledge-based shifts in intellectual development, participants may not have had an opportunity to adequately express epistemological changes in their understanding of their ethical commitments.

Despite these limitations, the current study makes important preliminary contributions to examinations of student counselors' professional ethical identity development. First, positive correlations existed across students' cognitive developmental domains of moral development, intellectual development, and professional ethical identity development. This study is the first to examine these three developmental theories in conjunction, as well as the first to examine the relationship of intellectual development and professional ethical identity development. Second, this study substantiates use of the MSOI for examinations of professional formation within the counseling profession. Globally, the current results were consistent with findings from studies of professional formation within legal, dental, military, and higher education contexts (Bartone et al., 2007; Bebeau \& Monson, 2009; Monson \& Hamilton, 2010). Finally, moral development was the most significant predictor of professional ethical identity development. Because gains in moral development may be achieved through deliberate psychological education strategies (i.e., involvement in significant and ongoing real-world experiences that are developmentally matched and provide both challenge and support to the individual), the significance of this finding for counselor preparation programs is profound (Cannon, 2008; Sprinthall, 1994). Strategies for promoting student counselor developmental growth and professional ethical formation are discussed in the following paragraphs.

\section{Implications for Counselor Preparation}

Counselor educators and supervisors help shape the professional identity of student counselors. If the ethical responsibilities and commitments that define the professional role are not clearly articulated or consistently transmitted, students' development of professional 
ethical identities can become muddled (V. A. Foster \& McAdams, 2009). Thus, although the current study examined student counselors' professional ethical identity development, the other side of this coin speaks to the professional ethical responsibilities of counselor educators, supervisors, and other leaders in the profession to help foster ethical identity development.

Lee Shulman (2010), president of the Carnegie Foundation, stated, "the most overlooked aspect of professional preparation was the formation of professional identity with a moral and ethical core of service and responsibility" (p. ix). Hamilton (2012) summarized critical tasks of professional education settings intending to target professional ethical identity development. First, attention to professional formation needs to be both comprehensive and explicit. Reliance on an acquisition of professional ethical identities through implicit facets of the program or student osmosis is insufficient. Counselor educators and supervisors can inform student counselors about the professional ethical responsibilities, commitments, and identities of counselors through program websites, mission statements, new student and clinical course work orientations, and course syllabi learning objectives or assignments, among other venues. Second, learning contexts should emphasize reflection on the responsibilities of the profession. Counseling courses on ethics can transcend a didactic emphasis on codes of ethics to also include how these guidelines relate to the ethical commitments and moral responsibilities inherent to counselors' professional ethical identities. For example, professors can include classroom discussions and journal prompts on various ethical dilemmas and how different courses of action may (or may not) reflect one's professional and/or personal values and commitments. Students may also consider how the professional ethical responsibilities of counselors differ from other professional contexts. Third, counselor educators should nurture programmatic cultures to support students' ongoing and active solicitation of feedback, critical dialogue, self-assessment, and personal reflection. Student counselors can assess and reflect on their own professional ethical identity development at training program milestones, and they can also receive specific feedback from faculty, supervisors, and peers about this growth. Finally, educators should tailor educational contexts to students' developmental stages. Without this scaffolding, students may not be able to endure the cognitive disruptions necessary for the development of more complex and functional frameworks of counselor professional ethical identity (Hamilton, 2012).

The results of this study also support the MSOI as a reflective tool that educators can use in counselor education programs. Through writing or discussion, students can respond to the essay questions related to definitions of professionalism, how these constructions were acquired, and anticipated challenges and conflicts inherent to the 
enactment of these professional roles. Monson and Hamilton (2010) provided specific instructor response strategies to student reflections according to each stage of professional ethical identity development. For example, because Stage 2 (independent operator) is characterized by more dualistic, self-motivated, and concrete role expectations, a primary goal becomes helping students to see experience in less black-and-white terms and to begin to consider the perspectives of others. At this stage of development, instructor responses to student reflections could include (a) "Does everyone see [this issue] as you do?" and (b) "Some people think there are situations which are not clearly right or wrong. Can you think of any examples?" (Monson \& Hamilton, 2010, p. 418). In contrast, at Stage 3 (team-oriented idealist), students are striving to be "good" members of the collective team. Developmentally matched instructor responses to guided reflections revolve around facilitating students' personal reflection on accepted values of the profession, addressing and resolving tensions between the values of the profession and one's personal values, and reframing failure into opportunities for learning. Sample responses to student reflections include (a) "How do you know that is true?" and (b) "Do different authorities disagree about that [issue]? What reasons do they use to come to their conclusion?" (Monson \& Hamilton, 2010, p. 420). Finally, targeted responses to students occupying or transitioning to Stage 4 (self-defining professional) may help them develop principled perspectives and become more tolerant of complexities inherent to professional roles. Monson and Hamilton (2010) suggested the following instructor responses: (a) "How do you know if you are seeing this issue clearly?" and (b) "How do you hold on to your core values in this sort of situation?" (p. 421).

\section{Implications for Further Research}

The construct of professional ethical identity (Bebeau \& Lewis, 2003; Monson \& Hamilton, 2010) provides a valuable guiding framework for future research related to counselor professional identity, including essential ethical commitments and responsibilities. As an extension of the data collected within the current study, participants' MSOI essay responses warrant a qualitative content analysis. Delineation of phrases, concepts, and anticipated personal or professional conflicts for student counselors at each developmental level supports delivery of scaffolded training interventions. Researchers could also use qualitative research methods to investigate the counselors' perceptions of professional ethical identity and its formation across a developmental continuum, including salient ethical responsibilities and moral commitments. Finally, we believe that studies should include a more holistic examination of the efficacy of counselor preparation programs and the current training standards in promoting professional formation. 
Professionals who serve the public must be motivated to put aside personal gain for the betterment of society and prioritize the interests of clients (Bebeau \& Monson, 2012; Riechel, 2013). Although counselors cannot be neutral or value free, counselors must become "aware of-and avoid imposing - their own values, attitudes, beliefs, and behaviors," and they should avoid "imposing their values onto clients, especially when the counselor's values are inconsistent with the client's goals" (ACA, 2014, Standard A.4.b.). Cultivating students' awareness of ethical standards of the profession is an exceedingly complex task because ethical codes and standards alone are insufficient. The results of this study support the relevance of both moral and intellectual developmental processes to student counselors' achievement of aligned professional ethical identities. To better meet the epistemological demands of the profession, counselors should facilitate students' movement away from more simplistic schemas for viewing self, others, and experience toward a richer understanding of complex perspectives, and, in doing so, hopefully, more aligned expressions of the professional identity of counselors become possible.

\section{References}

American Counseling Association. (2005). ACA code of ethics. Alexandria, VA: Author.

American Counseling Association. (2014). ACA code of ethics. Alexandria, VA: Author.

Auxier, C. R., Hughes, F. R., \& Kline, W. B. (2003). Identity development in counselors-intraining. Counselor Education and Supervision, 43, 25-38.

Bartone, P. T., Snook, S. A., Forsythe, G. B., Lewis, P., \& Bullis, R. C. (2007). Psychosocial development and leader performance of military officer cadets. The Leadership Quarterly, $18,490-504$.

Basseches, M. (2003). Adult development and the practice of psychotherapy. In J. Demick \& C. Andreoletti (Eds.), The handbook of adult development (pp. 533-564). New York, NY: Plenum Press.

Bebeau, M. J. (2008). Promoting ethical development and professionalism: Insights from educational research in the professions. University of St. Thomas Law Journal, 5, 336-403.

Bebeau, M. J., \& Lewis, P. (2003). Manual for assessing and promoting identity formation. Minneapolis: University of Minnesota, Center for the Study of Ethical Development.

Bebeau, M. J., \& Monson, V. E. (2012). Professional identity formation and transformation across the life span. In A. McKee \& M. Eraut (Eds.), Learning trajectories, innovation and identity for professional development (pp. 135-162). London, England: Springer.

Bebeau, M. J., \& Thoma, S. J. (2003). Guide for DIT-2. Minneapolis: University of Minnesota, Center for the Study of Ethical Development.

Cannon, E. (2008). Promoting moral reasoning and multicultural competence during internship. Journal of Moral Education, 37, 503-518.

Endicott, L., Bock, T., \& Narvaez, D. (2003). Moral reasoning, intercultural developmental, and multicultural experiences: Relations an cognitive underpinnings. International Journal of Intercultural Relationships, 27, 403-419. 
Foster, C. R. (2008). Identity and integrity in clergy formation. University of St. Thomas Law Journal, 5, 457-459.

Foster, V. A., \& McAdams, C. R., III. (2009). A framework for creating a climate of transparency for professional performance assessment: Fostering student investment in gatekeeping. Counselor Education and Supervision, 48, 271-284.

Gibson, D. M., Dollarhide, C. T., \& Moss, J. M. (2010). Professional identity development: A grounded theory of transformational tasks of new counselors. Counselor Education and Supervision, 50, 21-38.

Granello, D. H. (2002). Assessing the cognitive development of counseling students: Changes in epistemological assumptions. Counselor Education and Supervision, 41, 279-293.

Hamilton, N. (2012). Fostering professional formation (professionalism): Lessons from the Carnegie Foundation's five studies on educating professionals. Creighton Law Review, 45, 763-798.

Keeton v. Anderson-Wiley, 733 F. Supp. 2d 1368 (S.D. Ga. 2010).

Kegan, R. (1982). The evolving self. Cambridge, MA: Harvard University Press.

Kegan, R. (1994). In over our heads: The mental demands of modern life. Cambridge, MA: Harvard University Press.

Kohlberg, L. (1984). The psychology of moral development: The nature and validity of moral stages. San Francisco, CA: Harper \& Row.

Lahey, L., Souvaine, E., Kegan, R., Goodman, R., \& Felix, S. (1988). A guide to the subjectobject interview. Cambridge, MA: Harvard Graduate School of Education, Subject-Object Research Group.

Lambie, G. W., Hagedorn, W. B., \& Ieva, K. P. (2010). Social cognitive development, ethical and legal knowledge, and ethical decision making of counselor education students. Counselor Education and Supervision, 49, 228-246.

Lambie, G., Ieva, K., \& Mullen, P. R. (2011). Ego development, ethical decision-making, and legal and ethical knowledge in school counselors. Journal of Adult Development, 18, 50-59.

Leach, D. C. (2008). Medical profession and the formation of residents: A journey towards authenticity. University of St. Thomas Law Journal, 5, 526-529.

Linstrum, K. S. (2009). Ethical training, moral development, and ethical decision making in master's-level counseling students. Journal of College and Character, 10, 1-18.

Malek, M. O., Berger, D. E., \& Coburn, J. W. (2007). On the inappropriateness of stepwise regression analysis for model building and testing. European Journal of Applied Physiology, 101, 263-264.

McAuliffe, G. J., \& Lovell, C. (2006). The influence of counselor epistemology on the helping interview: A qualitative study. Journal of Counseling $\mathcal{E}$ Development, 84, 308-317.

Monson, V. E., \& Bebeau, M. J. (2009, April). Dental student professional identity development: Themes illustrative of development stage differences. Paper presented at the annual meeting of the American Education Research Association, Denver, CO.

Monson, V. E., \& Hamilton, N. W. (2010). Entering law students' conceptions of an ethical professional identity and the role of the lawyer in society. Journal of the Legal Profession, 35, 385-421.

Moore, W. S. (1987). The Learning Environment Preferences: Establishing preliminary reliability and validity for an objective measure of the Perry scheme of intellectual development. Dissertation Abstracts International: Section A. Humanities and Social Sciences, 49(6), 1186.

Moore, W. S. (1989). The Learning Environment Preferences: Exploring the construct validity of an objective measure of the Perry scheme of intellectual development. Journal of College Student Development, 30, 504-514.

Neukrug, E. S., \& Milliken, T. (2011). Counselors' perceptions of ethical behaviors. Journal of Counseling \& Development, 89, 206-216.

Nugent, F. A., \& Jones, D. (2009). Introduction to the profession of counseling (5th ed.). Upper Saddle River, NJ: Pearson/Merrill-Prentice Hall. 
Owens, E. W., \& Neal-McFall, C. W. (2014). Counselor identity development: Toward a model for the formation of professional identity. Journal of Counseling Leadership and Advocacy, $1,16-27$.

Perry, W. (1970). Forms of intellectual and ethical development during the college years. New York, NY: Holt, Rinehart \& Winston.

Rest, J. R. (1988). Report on DIT data analysis, account no. 5808. Minneapolis: University of Minnesota, Center for the Study of Ethical Development.

Rest, J., Narvaez, D., Bebeau, M., \& Thoma, S. J. (1999a). DIT-2: Devising and testing a new instrument of moral judgment. Journal of Educational Psychology, 91, 644-659.

Rest, J., Narvaez, D., Bebeau, M., \& Thoma, S. J. (1999b). Postconventional moral thinking: A neo-Kohlbergian approach. Hillsdale, NJ: Erlbaum.

Riechel, R. K. (2013). An investigation of relationships among school counselors' ethical identity development, moral reasoning, and attitudes toward confidentiality with minors (Unpublished doctoral dissertation). College of William \& Mary, Williamsburg, VA.

Shulman, L. E. (2010). Foreword: On the shoulders of Flexner. In M. Cooke, D. M. Irby, \& B. C. O'Brien (Eds.), Educating physicians: A call for reform of medical school and residency (pp. v-xii). Stanford, CA: Jossey-Bass.

Sprinthall, N. A. (1994). Counseling and social role taking: Promoting moral and ego development. In J. Rest \& D. Narvaez (Eds.), Moral development in the professions: Psychology and applied ethics (pp. 85-101). Hillsdale, NJ: Erlbaum.

Tennessee SB 1556/HB 1840. (2016). Amends Title 4, Title 49, and Title 63. Tennessee Code Annotated. 109th Gen. Assemb., Reg. Sess. Retrieved from http:/ /wapp.capitol.tn.gov/apps / Billinfo/default.aspx?BillNumber=HB1840\&ga=109

Ward v. Wilbanks, No. 09-CV-11237, Doc. 1 (E.D. Mich., Apr. 2, 2009).

Woo, H., Henfield, M. S., \& Choi, N. (2014). Developing a unified professional identity in counseling: A review of the literature. Journal of Counselor Leadership and Advocacy, 1, 1-15. 